Review Article

Sourabh Bhaskar, Mukesh Kumar*, and Amar Patnaik

\title{
Mechanical and Tribological overview of ceramic particulates reinforced aluminium alloy composites
}

https://doi.org/10.1515/rams-2019-0033

Received May 29, 2018; accepted Oct 04, 2018

Abstract: This review manuscript highlights the effects of various ceramic particulates on different aspects like tribological (sliding wear), mechanical and thermal behaviour etc. of aluminium alloy composites, across various operating parameters like normal load $(\mathrm{N})$, sliding velocity $(\mathrm{m} / \mathrm{s})$, sliding distance $(\mathrm{m})$, temperature $\left({ }^{\circ} \mathrm{C}\right)$, reinforcement weight percentage. It also discusses different fabrication techniques of such composites as reported by various scholars. Such advanced alloyed-composites find frequent applications in automotives, military, marine, structural, etc. applications, where tribo-logical phenomenon plays a dominant role. The material scientists world-wide are actively engage in improving life of such components by enhancing their mechanical, physical, chemical etc. properties along with improvement in wear resistance in a costeffective manner. This overall enhances the working efficiency of the component in required applications. Single or binary or hybrid ceramic reinforcement with varying content is explored by scholars and has ample scope of further exploration. It has been concluded from the literature review that ceramic reinforcement lead to significant enhancement in mechanical, tribological and thermal characteristics of Al alloy based MMCs. Further, the micro-sized ceramic particulates increase the interfacial bond strength between the matrix-reinforcement that enhances effective load transfer and sustain it at various tribological operating parameters, that further validated by surface morphology studies.

Keywords: Aluminium alloy; Metal matrix composite; Ceramic particulates; Tribology; Mechanical properties

\footnotetext{
*Corresponding Author: Mukesh Kumar: Department of Mechanical Engineering, Malaviya National Institute of Technology, Jaipur-302017, Rajasthan, India; Email: mukeshyss@gmail.com; Tel.: +919549654506

Sourabh Bhaskar, Amar Patnaik: Department of Mechanical Engineering, Malaviya National Institute of Technology, Jaipur302017, Rajasthan, India
}

\section{Abbreviations}

\author{
AMC Aluminium Matrix Composite \\ ANOVA Analysis of Variance \\ CTE Coefficient of Thermal Expansion \\ DOE Design of Experiment \\ FSP Friction Stir Processing \\ MMC Metal Matrix Composite \\ MML Mechanically Mixed Layer \\ RSM Response Surface Methodology \\ UTS Ultimate Tensile Strength
}

\section{Introduction}

MMCs provide superior mechanical strength, stiffness and wear resistance to different components used in various fields such as structural, aerospace, automotive, etc. Different ceramic particulates as reinforcing materials are silicon carbide $(\mathrm{SiC})$, silicon nitride $\left(\mathrm{Si}_{3} \mathrm{~N}_{4}\right)$, boron nitride (BN), alumina $\left(\mathrm{Al}_{2} \mathrm{O}_{3}\right)$, aluminium nitride (AlN), titanium nitride (TiN), magnesium oxide ( $\mathrm{MgO}$ ) etc. Aluminium, titanium and magnesium alloys are some of the metal matrix materials that are frequently used to fabricate MMCs. The AMCs filled with micro sized particulates (ceramics/inter-metallic) reinforcements are found to reveal improved properties like hardness, specific strength/stiffness, thermal resistance, wear resistance and corrosion resistance as compared with the unreinforced alloy. Generally, the ceramic particulates increase the yield and ultimate strength of the parent alloy, but it adversely affects the ductility property. The degree of such improved properties is reported to be function of reinforcement nature and fabrication techniques employed that in turns determines interfacial properties between matrixreinforcement. To elaborate these facts, this review article has been classified according to the following mentioned aspects of Aluminium alloyed composites. 
- On tribological characteristics of Aluminium alloyed composites.

- On physical and mechanical characteristics of Aluminium alloyed composites.

- On fabrication of Aluminium alloyed composites.

- On thermal and thermo-mechanical behaviour of Aluminium alloyed composites.

\section{On tribological characteristics of Aluminium alloyed composites}

The operating variables that govern sliding tribology of materials are normal applied load, sliding speed, sliding distance, temperature, counter surface hardness, etc. The working range of these variables is an important consideration in real time evaluation of tribological performance as well as service life of components. This fact has been advocated by research of eminent scholars like Kumar et $a l$. [1] discussed the sliding wear characteristics under unlubricated conditions of $\mathrm{Al} 2618$ metal matrix composite reinforced with $\mathrm{ZrB}_{2}, \mathrm{Si}_{3} \mathrm{~N}_{4}$ and AlN-particles up to $8 \mathrm{wt} . \%$. Fabrication was processed through stir casting technique. The Taguchi orthogonal array was used to design the experimentation and ANOVA was applied to find out the effect of each factor on the wear rate. Load was the most significant factor because it was found that specific wear rate slightly enhanced for a load range of $10 \mathrm{~N}-50 \mathrm{~N}$ load, but it increases sharply at $50 \mathrm{~N}$ load for a reinforcement of 8 wt.\%. Abrasive and adhesive wear were dominant mechanisms observed for lower and higher load conditions respectively. Yuan et al. [2] examined the influence of boron content on the wear and friction characteristics using scratch test of the AMCs (Aluminium matrix composites) and pure aluminium. AMCs filled with $\mathrm{AlB}_{2}$ - particles have been produced by powder metallurgy followed by hot rolling. Scratch tests have been performed for a load range of $0.1 \mathrm{~N}$ to $30 \mathrm{~N}$, a scratch length of $3 \mathrm{~mm}$ and for two different sliding velocities like 15 and $45 \mathrm{~mm} / \mathrm{min}$. It was observed that under the given conditions the wear resistance of the pure aluminium has been increased due to the formation of in-situ $\mathrm{AlB}_{2}$-particles. The wear area and friction coefficient of the composites have also been increased as the applied load increases.

Dinaharan et al. [3] evaluated the wear rate of AA6082 AMCs reinforced with different ceramic particulates such as $\mathrm{SiC}$, alumina, $\mathrm{TiC}$ and $\mathrm{B}_{4} \mathrm{C}$. The composites were fabricated through FSP technique and effect of various FSP parameters on the wear rate was estimated using some empirical relationships by applying RSM. Lower wear rate and higher micro-hardness were obtained for TiC-particles reinforced composites. Minimum wear rate was also obtained for low tool rotational speed, high traverse speed and maximum groove width. Dinaharan et al. [4] have evaluated the sliding wear behaviour of AA6061 matrix composites reinforced with industrial waste fly ash particulates. The composite was fabricated through friction stir processing technique. Pin-on-disc apparatus has been used for conducting the wear experiments. The wear resistance was increased by increasing the volume fraction of fly-ash particles and maximum wear resistance was obtained for $18 \%$ volume fraction. The enhanced microhardness due to the grain refinement was the main reason for the improved wear resistance of AMCs. Characterization of AMCs was also done through optical microscopy, scanning electron microscopy. Homogeneous distribution of fly ash particles was observed in AMCs. Alaneme and Sanusi [5] have analysed the wear properties of $\mathrm{Al}-\mathrm{Mg}$ Si alloy matrix composites filled with alumina, rice husk ash and graphite particles fabricated through stir casting method. Wear tests were performed using Taber abrasion wear testing machine. Improved wear resistance was obtained for $73.5-74.5 \%$ alumina, $25 \%$ rice husk ash and $0.5-1.5 \%$ graphite. The composites without graphite had shown more wear than those containing graphite particles. The improved wear behaviour was due to the lubricating effect of graphite particles which formed a layer between the two mating surfaces. It was also found that wear resistance has been reduced as the amount of graphite increased from 0.5 to $1.5 \%$.

Pramanik [6] reported the influence of different sliding parameters such as sliding distance, pressure and sliding speed on the wear properties of AA6061 matrix composite reinforced with 10 volume $\% \mathrm{Al}_{2} \mathrm{O}_{3}$ particles. Wear tests were performed on pin-on-disc testing machine. It was shown that the wear loss was much lowered for composite when compared with base alloy with all the changing factors like pressure, distance and speed. The possible wear mechanism for composite was three body abrasion wear. The filled alumina particles provide resistance to the deformation of composite surface and enhanced the wear characteristics of the composite.

Kumar et al. [7] investigated the tribological properties of AA6061-T6/AlN ${ }_{p}$ composite fabricated through liquid metallurgy route. A regression model was developed for predicting the wear characteristics under sliding conditions of AA6061 matrix composite reinforced with AlN particulates. A central composite design was applied for designing the experiments and pin-on-disc testing machine was used for conducting the experimentations. It was found that the wear loss of the composite increased by 
increasing the sliding velocity, distance and normal load. The wear loss of the composite was decreased by increasing in mass fraction of AlN particles from 0 to $20 \%$. Delamination was the main wear mechanism observed at larger sliding velocity. Ploughing and abrasive wear mechanisms were also obtained. Adhesive wear mechanism was more effective in AA6061 alloy, whereas abrasive wear was effective in AA6061/AlNp composites. Ravindran et al. [8] fabricated the hybrid AA2024 matrix composites reinforced with fixed 5 wt. $\%$ of graphite and varied (5, 10, 15, $20 \mathrm{wt} . \%)$ of $\mathrm{SiC}$ particles through powder metallurgy process. Sliding wear experiments were conducted as per the ASTM G99-05 standard on pin-on-disc machine. Various controlling parameters were used such as load ( 5 to $30 \mathrm{~N}$ ), varying sliding distance (1000 or $3000 \mathrm{~m}$ ) and sliding speeds ( 1 and $2 \mathrm{~m} / \mathrm{s}$ ). The wear rate was found to be decreased by increasing the content of $\mathrm{SiC}$ particles due to the increased hardness of the composite with the addition of hard ceramic particulates. The wear resistance decreased by increasing the normal load and sliding distance. The lower wear loss was observed for $20 \mathrm{wt} . \% \mathrm{SiC}$ and $5 \mathrm{wt} . \%$ graphite reinforced aluminium matrix composite. Kumar and Dhiman [9] have evaluated the specific wear rate of the hybrid AA7075 MMCs filled with SiC (7 wt.\%) as hard ceramic particles and graphite ( $3 \mathrm{wt} . \%)$ as soft solid lubricant. Liquid metallurgy technique was used for the production of composites. Design of experiments was done according to full factorial method. Specific wear rate was examined on pin-on-disc wear tester and influence of various sliding factors on wear behaviour was discussed. The wear rate has been reduced at low load in the range of 20 $40 \mathrm{~N}$ and at low speed in the range of 2-4 m/s. Rajmohan et al. [10] have fabricated the hybrid aluminium matrix composite reinforced with mica and $\mathrm{SiC}$ particles. These particles were added into $\mathrm{Al} 356$ alloy used as matrix material and composite was fabricated through liquid metallurgy method. Pin-on-disc machine was used to perform the experimentation under dry conditions. Experimentation was designed using the central composite face centred second order design and the effect on three parameters (load, sliding speed, amount of mica particles) has been investigated. It was observed from the response surface graph that the wear loss was found to enhanced with the increasing load and wear loss was marginally reduced by increasing the sliding speed. The ANOVA showed that load was the most influencing parameter affecting the wear loss of composites and after that mass fraction of mica.

Devaraju et al. [11] discussed the influence of adding $\mathrm{Gr} / \mathrm{Al}_{2} \mathrm{O}_{3}$ with $\mathrm{SiC}$-particles on the wear behaviour of AA6061-T6 surface hybrid composites fabricated through friction stir processing. The dry sliding wear experiments were done as per ASTM standard G99-05 on pin-on-disc apparatus. The $\mathrm{Al}-\mathrm{SiC} / \mathrm{Gr}$ surface hybrid composites have shown improved wear resistance than the $\mathrm{Al}-\mathrm{SiC} / \mathrm{Al}_{2} \mathrm{O}_{3}$ surface hybrid composites, due to the lubrication effect of graphite particles. The wear loss has been increased by increasing the sliding distance for all the composites and for the Al alloy. Mazahery and Shabani [12] examined the wear characteristics of unreinforced AA6061 alloy and composites reinforced with $\mathrm{SiC}$ particles $(5,10,15$ volume fraction) using pin-on-disk apparatus. The composite was fabricated by compo-casting technique. The dry sliding wear experiments were conducted under the varying loads of 10 to $40 \mathrm{~N}$ and with a sliding velocity of $0.3 \mathrm{~m} / \mathrm{s}$. The wear rate was found to be reasonably decreased for unreinforced alloy as well as for all the composites by increasing the sliding distance and minimum wear rate was obtained for the $15 \%$ volume fraction of $\mathrm{SiC}$ reinforced composite at $10 \mathrm{~N}$ applied load. Load was found to be the most significant parameter affecting the wear loss of the composites. Mazahery and Shabani [13] evaluated the sliding wear behaviour of AA2024 alloy matrix composite reinforced with various volume fractions $(0,5,10,15,20,25,30)$ of coated $\mathrm{B}_{4} \mathrm{C}$ particles fabricated by squeeze casting method. The weight loss was observed for varying sliding distances $(0$, $200,400,600,800,1000 \mathrm{~m}$ ). The fabricated composite had more wear resistance as compared to the matrix alloy and improved with higher particle content. It was also found that the weight loss was increased by increasing the sliding distance for unreinforced alloy and for all the composites. Minimum weight loss was obtained for the composite reinforced with $30 \%$ volume fractions.

Das et al. [14] investigated the sliding wear characteristics of $\mathrm{Al}-\mathrm{Zn}-\mathrm{Mg}-\mathrm{Cu}$ alloy composite filled with $10 \mathrm{wt} . \%$ SiC-particles. The composite was fabricated through liquid metallurgy technique. Pin-on-disc wear tester was used for conducting the experimentation with varying applied loads, sliding distances. The wear rate decreases with the addition of SiC-particles because these hard particles provide protection against the counter surface material by restricting the deformation. The wear rate increased by increasing in applied load. It was also observed that the sliding wear was also affected by the formation of Mechanically Mixed Layer (MML) which was formed due to the transfer of counter surface material. Ravindran et al. [15] discussed the sliding wear and friction characteristics of hybrid aluminium alloy 2024 matrix composite filled with 5 wt.\% of $\mathrm{SiC}$ and $0,5,10 \mathrm{wt} . \%$ of graphite particles as solid lubricants. Pin-on-disk apparatus was used for conducting the experimentation and effect of various sliding parameters such as load (10 and $20 \mathrm{~N}$ ), sliding speed (1 and $2 \mathrm{~m} / \mathrm{s}$ ), sliding distance (1000 and $3000 \mathrm{~m}$ ) and weight 
percentage of reinforcing particles on wear and friction was discussed using ANOVA. It was found that the wear increased by increasing the load and sliding distance but decreased by increasing the sliding speed from $1 \mathrm{~m} / \mathrm{s}$ to 2 $\mathrm{m} / \mathrm{s}$. Minimum wear loss was observed for $5 \mathrm{wt} . \%$ graphite and SiC-particles. Rao and Das [16] examined the influence of $\mathrm{SiC}$ weight content $(10,15,25)$ and various values of sliding velocity $(0.52,1.72,3.35,4.18,5.23 \mathrm{~m} / \mathrm{s})$ on the wear behaviour $\mathrm{Al}-\mathrm{Zn}-\mathrm{Mg}$-Cu matrix composite using pinon-disc wear tester under a fixed applied pressure of 0.2 $\mathrm{MPa}$ and constant sliding distance of $5000 \mathrm{~m}$. The wear resistance of the alloy was enhanced significantly due to $\mathrm{SiC}$ addition. The wear resistance was increased by increasing $\mathrm{SiC}$ content for different values of sliding speeds and decreased by increasing sliding speeds. The improved wear resistance was due to the decrease in the degree of effective contact between two mating surfaces as the number of SiCparticles increases. Sahin and Kilicli [17] have evaluated the influence of applied load and weight fraction under the abrasive wear conditions of AA2014 MMCs reinforced with SiC-particles. The composite was fabricated through liquid metallurgy technique. The wear properties were in vestigated for various factors such as abrasive particle size $(50 \mu \mathrm{m})$, weight fraction (10\%) and applied load $(0,5,10$, $15,20,25,30,35 \mathrm{~N})$ using pin-on-disc apparatus. The wear resistance of the aluminium matrix composite was found to be increased by increasing the weight percentage of SiCparticles. By increasing the applied load, the value of wear rate also increased but lowered wear rate was obtained for $10 \mathrm{wt} . \% \mathrm{SiC}$-particles when compared with the base alloy.

Rao and Das [18] investigated the sliding wear behaviour of high strength aluminium alloys such as AA7010, AA7009, AA2024 and influence of SiC addition on the sliding wear of AMCs. The composite was fabricated through stir casting technique. The sliding wear tests were performed on pin-on-disc wear apparatus with various applied pressure and fixed sliding speed and also for various volume fractions. Improved wear properties were obtained by increasing the number of the SiC-particles addition. Lowest wear rate was obtained for AA7010 alloy composite and highest wear rate was obtained for AA2024 alloy composite irrespective of the $\mathrm{SiC}$ amount. Kumar et al. [19] examined the dry sliding wear behaviour of AA6351 matrix composite reinforced with $\mathrm{ZrB}_{2}$ particles. The composite was fabricated through in-situ fabrication technique. The sliding wear tests at room temperature and under dry conditions were performed on pin-on-disc wear tester as per the ASTM G99-95 with different weight percentage $(0,3$, 6, $9 \mathrm{wt} . \%$ ) of reinforcement particles, fixed load of $9.8 \mathrm{~N}$, fixed sliding speed of $1 \mathrm{~m} / \mathrm{s}$ and time was $20 \mathrm{~min}$. The wear rate was found to be decreased by increasing the content of
$\mathrm{ZrB}_{2}$ particles. Higher wear resistance was due to the high peak hardness and better interfacial bonding between matrix and reinforcement particles added by in-situ reaction. Rajeev et al. [20] investigated the effects of various operating parameters such as applied load (15 and $45 \mathrm{~N}$ ), sliding distance (500 and $1500 \mathrm{~m}$ ), reciprocating velocity (0.2 and $0.4 \mathrm{~m} / \mathrm{s})$, counter surface temperature $\left(60\right.$ and $\left.120^{\circ} \mathrm{C}\right)$ and weight content of silicon particles ( 6 and $18 \mathrm{wt} . \%$ ) on dry reciprocating wear characteristics of A319, A390 MMCs filled with SiC-particles. Pin-on-plate test apparatus was used for conducting the experimentation in reciprocating conditions with frequency of $1-2 \mathrm{~Hz}$, the wear track length of $100 \mathrm{~mm}$. Fractional factorial design was applied for designing the experiments. ANOVA has been adopted to find out the influence of each factor. Higher wear resistance was observed for the higher amount of silicon particles addition. Applied normal load, distance of sliding, reciprocating velocity and silicon content were the most influential controlling factors affecting the wear rate of composite specimens. Counter surface temperature had very small effect on the wear behaviour of AMCs. Natarajan et al. [21] have fabricated the $\mathrm{AA} 6063 / \mathrm{TiB}_{2}$ in-situ aluminium matrix composite and evaluated the dry sliding wear characteristics under the influence of various loads $(9.8,19.6,29.4$ $\mathrm{N})$ and temperatures $\left(100,200\right.$ and $\left.300^{\circ} \mathrm{C}\right)$ using Pin on Disc apparatus. Some parameters were fixed such as sliding speed (400 rpm), time (20 min), wear track diameter (40 mm). The wear resistance was improved by increasing the number of $\mathrm{TiB}_{2}$ particles, but wear rate was found to be increased by increasing values of loads. The wear rate of the base alloy and its composites was increased as the temperature increases up to $100^{\circ} \mathrm{C}$ and wear rate increases sharply around $200^{\circ} \mathrm{C}$, after this as temperature further increased, the wear rate also increased gradually. The increased in wear rate at high temperature was attributed to the transition of wear from mild to the severe conditions.

Kok [22] have discussed the abrasive wear of $\mathrm{Al}_{2} \mathrm{O}_{3}$ particles reinforced AA2024 alloy composite considering the effect of alumina particles content (10,20, $30 \mathrm{wt} . \%)$ and size $(16$ and $66 \mu \mathrm{m})$, sliding distance and abrasive grit size. The composite was fabricated through stir casting method. Abrasive wear tests were done with emery papers of various sizes, at room temperature and water was used as a lubricant. Various sliding parameters were used such as normal load $(2 \mathrm{~N})$, sliding velocity $(2 \mathrm{~m} / \mathrm{s})$ and sliding distance $(0-450 \mathrm{~m})$. The wear resistance of AMC was enhanced with the addition of alumina particles. The wear of the aluminium composite decreased as the content and size of alumina particles increased.

Zhiqiang et al. [23] reported the wear in dry sliding conditions of $\mathrm{Al}-\mathrm{Cu}-\mathrm{Mg}$ alloy matrix reinforced with sili- 
con particles (9 volume fraction). The composite was fabricated through powder metallurgy technique. Different wear parameters such as applied loads (20 to $100 \mathrm{~N}$ ) and sliding speeds $(0.3$ to $0.8 \mathrm{~m} / \mathrm{s})$ were used to determine the wear resistance of aluminium matrix composite using ringon-rock wear test apparatus. The wear resistance was decreased as the sliding speed and normal load increases for base alloy as well as for the composite. Lower wear loss was achieved for the Si particles reinforced composites as compared with the base alloy. Mondal et al. [24] added the $25 \mathrm{wt} . \% \mathrm{SiC}$ particulates in Al-Zn-Mg alloy (AA7009) to determine the sliding wear characteristics of AMCs in dry sliding conditions. The composite was fabricated by stir casting method and particle size of reinforcement was taken in the range of 20 to $40 \mu \mathrm{m}$. Wear has been analysed under fixed speed of $3.35 \mathrm{~m} / \mathrm{s}$ and different loads varying from 0 to $2.5 \mathrm{MPa}$ and sliding distance was $5000 \mathrm{~m}$. The addition of $\mathrm{SiC}$ particles in the base alloy matrix decreased the wear loss of the composite. This was due to the higher surface roughness which reduces the contact between the wear specimen and counter surface material. The wear loss was increased slightly for all the specimens with the applied load up to 1.5 MPa but after this load, the wear loss was sharply increased. Sahin [25] determined the effect of various sliding conditions (reinforcement size, applied load, abrasive grain size and sliding distance) on the wear properties of AA2014 alloy composites reinforced with $10 \mathrm{wt} . \%$ SiC-particles with two different particles sizes (50 and 100 $\mu \mathrm{m})$. The composite was fabricated through liquid metallurgy technique and experiments were designed using Taguchi design of experiment. ANOVA was applied to find out the contribution of various controlling factors on the abrasive wear behaviour. Pin-on-disc wear tester was used with emery paper for providing the abrasive medium It was observed that the grain size of the abrasives and the reinforcement size were the two factors which greatest influenced the wear of aluminium matrix composite. The sliding distance and applied load were the two factors which have not significantly affected the wear of fabricated composite.

Suresh et al. [26] observed the dry sliding wear of $\mathrm{Al}$ Si-Mg alloy matrix composite reinforced with Beryl- particles $(0,2,4,6,8,10 \mathrm{wt} . \%)$ for different sliding distances $(600,1200,1800,2400 \mathrm{~m})$ and fixed normal applied load of $10 \mathrm{~N}$. The composite was fabricated through squeeze casting and gravity casting technique. The wear resistance of the composite was improved with the addition of reinforcements due to the improved hardness of the composite. The wear loss was found to be increased by increasing the sliding distance both for the gravity cast and squeeze cast samples. Tee et al. [27] have analysed the dry slid- ing wear of $\left(5,10,15\right.$ vol.o\%) of $\mathrm{TiB}_{2}$ reinforced $\mathrm{Al}-\mathrm{Cu}$ matrix composite using pin-on-disk apparatus. The composite was fabricated through stir casting route. It was noticed that though the wear resistance of the AMC was increased by increasing content of $\mathrm{TiB}_{2}$ - particles but due to the formation of $\mathrm{Al}_{3}$ Ti phase, there was not much improvement in the wear resistance for 15 vol.\% particles reinforced composite and almost similar results were obtained for 5 and 15 volume \% reinforcement. Al-Rubaie et al. [28] examined the abrasive wear behaviour in two body wear conditions of SiC-particles reinforced AA1100 alloy matrix composite with different volume fractions (5, 10, 20 vol.\%) of reinforcement. Aluminium matrix composite was fabricated by powder metallurgy technique. Pin-on-disc abrasion wear tester was used for conducting the experimentations along with silicon carbide and alumina abrasives of different grit sizes ranging from 20 to $60 \mu \mathrm{m}$. Lower wear resistance was observed as the abrasive grit size increased and improved wear resistance was obtained for SiC particles reinforced composite when sliding against the alumina abrasives rather than sliding against silicon carbide abrasives.

Wilson and Alpas [29] studied the dry sliding wear of two aluminium alloys AA6061 and A356 cast alloy reinforced with 20 vol.\% $\mathrm{SiC}$ and 20 vol. $\% \mathrm{Al}_{2} \mathrm{O}_{3}$ ceramic particles and a hybrid composite having both $\mathrm{SiC}$ and 10 vol.\% graphite reinforcement. The influence of temperature varying from room temperature to $460^{\circ} \mathrm{C}$ on the sliding wear behaviour was investigated. The wear tests were performed on ring-on-flat wear apparatus at a speed of 1 $\mathrm{m} / \mathrm{s}$ and load of $11.55 \mathrm{~N}$. It was found that for unreinforced aluminium alloys the wear mechanism has been changed from mild to severe wear conditions for the given temperature range. The wear resistance was found to be increased for given temperature range with the addition of $\mathrm{Al}_{2} \mathrm{O}_{3}$ and SiC-particles. For hybrid composite, incorporation of graphite particles reduced the strength of the alloy due to its self-lubricating property. Sannino and Rack [30] done the investigation for the wear and friction behaviour of AA2009 alloy composite filled with 20 vol.\% SiC-particles of varying size from 4 to $29 \mu \mathrm{m}$ and also observed the effect of particulate size and matrix aging on wear and friction behaviour of AMC. Composite was fabricated through powder metallurgy technique. Pin-on-ring wear tester was used for conducting the experimentation with a normal load of $14.2 \mathrm{~N}$, sliding velocity of $0.36 \mathrm{~m} / \mathrm{s}$, sliding distance $3600 \mathrm{~m}$ and at room temperature. It was found that as the particulate size increase the friction coefficient also increases. Wear rate also enhanced with larger particulate size. 


\section{On physical and mechanical characteristics of Aluminium alloyed composites}

Aluminium alloy composites provide enhanced physical and mechanical properties along with superior thermal and electrical conductivity, good fatigue and fracture properties. Some of these characteristics are tensile strength, hardness, flexural strength, impact strength and density. The optimum values of all these properties are greatly influenced by the weight content of filled ceramic particulates along with the size of the particles. These facts are explained in the research reports of various scholars like Hong et al. [31] investigated the mechanical properties of 7 wt.\% $\mathrm{TiB}_{2}$-particles reinforced $\mathrm{Al}$-Cu-Li matrix composite. The composite was fabricated by in-situ reaction technique and the density of the composite was measured by Archimedean method. The tensile test was performed for a strain rate of $1 \times 10^{-3} \mathrm{~s}^{-1}$ and Vickers hardness test was done under a load of $30 \mathrm{~kg}$. The mechanical properties of composite were improved as compared with the unreinforced alloy with the addition of $\mathrm{TiB}_{2}$ particles. Reduction in the average grain size of the particles and uniform distribution were the two main components that enhanced the mechanical properties of the composites. Selvam and Dinaharan [32] have fabricated the $\mathrm{AA} 7075 / \mathrm{ZrB}_{2} \mathrm{AMC}$ with 0 , 3, 6, 9 and 12 wt.\% of $\mathrm{ZrB}_{2}$-particles by using in-situ fabrication method and various mechanical properties have been investigated. It was reported that mechanical properties like hardness and ultimate tensile strength of AMC was significantly improved by increasing in $\mathrm{ZrB}_{2}$ content. The strength of the composite was enhanced due to the grain refinement done by $\mathrm{ZrB}_{2}$-particles and also due the fine distribution of particles in the matrix resulted in increased orowan strengthening. Effective load transfer capacity of the matrix to the reinforcement and superior interfacial connection between the matrix and reinforcement also improved the strength of the composites.

Sharma et al. [33] reported the fabrication of AA6082T6 matrix composite reinforced with $(0,3,6,9,12$ wt.\%) $\mathrm{Si}_{3} \mathrm{~N}_{4}$-particles and produced through stir casting technique. Various mechanical properties of composite have also been investigated. The density of the fabricated composite was increased by increasing the number of reinforced particles because density of $\mathrm{Si}_{3} \mathrm{~N}_{4}$ particles is more as compared with the matrix alloy. Micro-hardness, Macrohardness and UTS of the composite were found to be enhanced by increasing the weight content of $\mathrm{Si}_{3} \mathrm{~N}_{4}$-particles. These improvements in the properties were achieved by the increased surface area of reinforcement particles into the $\mathrm{Al}$ matrix which decreased the grain size of $\mathrm{Al}$ matrix and provide resistance to the plastic deformation. Iacob et al. [34] investigated the micro-hardness of pure aluminium matrix composite reinforced with $\mathrm{Al}_{2} \mathrm{O}_{3}$ as hard ceramic particles and graphite powder as a solid lubricant. Fabrication of the composite was done by powder metallurgy technique. Micro-hardness test was done on the hybrid composite for a load of $15 \mathrm{~g}$ and $15 \mathrm{~s}$ duration on Vickers hardness tester. It was found that the micro-hardness of the hybrid composite was enhanced due to the extended duration of milling and also by increasing the amount of reinforcement. This may be due to the fine grain size increment which raised the fragmentation of both the reinforcements and as a result of this homogeneous distribution was achieved. Bauri et al. [35] fabricated AA5083 MMC reinforced with tungsten (W) particles through friction stir processing. The mechanical and micro-structural properties were investigated and also compared with unprocessed AA5083 alloy and unreinforced friction stir processed AA5083. The ultimate tensile strength was improved as compared with the base alloy and friction stir processed alloy without tungsten particle addition while ductility remains at higher level. It can be attributed to the effective load transfer efficiency of the matrix to the particles due to superior interface boding between the Al matrix and W particles. Ghanaraja et al. [36] discussed the fabrication of in-situ AA1100 AMC reinforced with (0, 3, 6, 9, 12 wt.\%) $\mathrm{TiO}_{2}$-particles. Various mechanical properties were also evaluated for the composite and compared with the base alloy matrix. It was shown that the Brinell hardness of AMC reinforced with $\mathrm{TiO}_{2}$-particles enhanced by increasing the amount of the reinforcement. Percentage elongation also increased by increasing $\mathrm{TiO}_{2}$ powder up to $9 \%$. Tensile strength and yield strength of AMC have shown increasing trend with the weight content of $\mathrm{TiO}_{2}$-particles and maximum values of both the properties have been obtained for $12 \mathrm{wt} . \%$ particles addition.

Gautam and Mohan et al. [37] have investigated the influence of $\mathrm{ZrB}_{2}$-particle addition on the mechanical properties of AA5052 hybrid composite reinforced with $(0,1$, 3, 5 vol.\%) $\mathrm{ZrB}_{2}$-particles and fixed amount of $10 \mathrm{vol} . \%$ $\mathrm{Al}_{3} \mathrm{Zr}$-particles. Composite was fabricated through direct melt reaction technique. The ultimate tensile strength and yield strength of composite were increased by increasing the content of $\mathrm{ZrB}_{2}$-particles up to 3 vol.\% but after this amount the ultimate tensile strength and yield strength have been reduced. Percentage elongation was also increased up to 1 vol.\% particle addition but after this it was reduced and reached at minimum level for $10 \mathrm{vol} . \%$ particle addition. Bulk hardness of the composite was en- 
hanced by increasing the volume content of $\mathrm{ZrB}_{2}$-particles. Improvement in mechanical properties was obtained by the reduction of grain size of matrix due to the addition of $\mathrm{ZrB}_{2}$-particles. Han et al. [38] evaluated the mechanical properties along with fracture mechanisms of in-situ fabricated $\mathrm{Al}-\mathrm{Si}$ alloy composite with $4 \mathrm{wt} . \% \mathrm{TiB}_{2}$-particles at high temperature ranging from 25 to $350^{\circ} \mathrm{C}$. The elastic modulus of the composite was found to be enhanced with the addition of $\mathrm{TiB}_{2}$-particles but was reduced at higher temperature both for the Al-Si alloy and $\mathrm{TiB}_{2}$ reinforced composite. The yield strength and tensile strength of both the alloy and composite have shown higher values at room temperature but decreasing trend was observed as temperature increases from 100 to $350^{\circ} \mathrm{C}$. The percentage elongation was increased both for the alloy and composite by increasing the temperature.

Kumar et al. [39] reported the in-situ fabrication of AA5052 matrix composite reinforced with $(0,3,6,9,10$ vol.\%) $\mathrm{ZrB}_{2}$-particles and investigated the various mechanical properties. Density of the fabricated composite was increased with the addition of $\mathrm{ZrB}_{2}$-particles. The Ultimate tensile strength and yield strength of AMC were increased by increasing the number of $\mathrm{ZrB}_{2}$-particles up to $9 \%$ volume fraction but after that both the properties were decreased due to the occurring of the crack nucleation sites at the interface of both the matrix and particles. Hardness of the composite was continuously increased as the content of $\mathrm{ZrB}_{2}$ increased. Ductility of the composite enhanced significantly compared to the matrix alloy. The overall improvement of mechanical properties may be due to the better bonding between particles and $\mathrm{Al}$ matrix. Khosroshahi et al. [40] have fabricated three types of A356 cast alloy composites reinforced with 3 wt. $\% \mathrm{Al}_{2} \mathrm{O}_{3}, 3$ wt. $\% \mathrm{SiC}$ and a mixture of equal weight content of $3 \mathrm{wt} . \%\left(\mathrm{Al}_{2} \mathrm{O}_{3}+\mathrm{SiC}\right)$. Stir casting followed by rolling was used for the fabrication of composite, copper coating was done on the reinforcement in order to improve the wettability of particles with the matrix. It was found that the composite having fine $\mathrm{SiC}$ and coarse $\mathrm{Al}_{2} \mathrm{O}_{3}$ particles contains highest strengths and hardness. It may be due to the fact that electro-less deposition of copper coating on to the reinforced particles improved the wettability of the ceramic particles by aluminium alloy. Suresh et al. [41] investigated the mechanical characteristics of AA6061 alloy matrix composite reinforced with $\left(0,2,4,6,8,10\right.$ wt.\%) $\mathrm{TiB}_{2}$-particles. Composite was fabricated through high energy stir casting technique. Hardness of the composite was enhanced with the addition of $\mathrm{TiB}_{2}$-particles. The ultimate tensile strength and fracture strength of the composite were enhanced as compared with the unreinforced alloy by increasing content of $\mathrm{TiB}_{2}$-particles. From the morphology study it was revealed that superior bonding between matrix and reinforcement results in enhanced mechanical properties. The percentage elongation reduces due to the hard $\mathrm{TiB}_{2}$ reinforcement.

Dwivedi et al. [42] fabricated the A356 MMC reinforced with (5, 10, 15 wt.\%) SiC particles through electromagnetic stir casting method. It was observed that the type of fabrication process and content of reinforcement enhanced the mechanical properties of aluminium matrix composite filled with SiC-particles. The tensile strength of the composite was enhanced by increasing the number of SiCparticles due to high dislocation density provided by the hard SiC-particles that resist the plastic deformation of $\mathrm{Al}$ matrix. Similar trend was noticed for impact strength and fatigue strength.

Kai et al. [43] have fabricated the aluminium matrix composite reinforced with $32 \mathrm{vol} . \% \mathrm{~B}_{4} \mathrm{C}$-particles through flake powder metallurgy. Various mechanical characteristics such as yield strength, UTS and percentage elongation have been evaluated. It was reported that the strength and ductility of particulate filled AMCs were improved by adding of $\mathrm{B}_{4} \mathrm{C}$-particles. It was found that flake powder metallurgy enhanced the uniform distribution of reinforced particles and thus improved the mechanical properties like yield strength, ultimate tensile strength and ductility of the composites as compared to conventional powder metallurgy technique. Zheng et al. [44] found the influence of adding $\mathrm{B}_{4} \mathrm{C}$-particles on strength and ductility of AA2024 matrix composite fabricated through mechanical milling followed by hot extrusion. When $\mathrm{B}_{4} \mathrm{C}$-particles content was more than 20 vol.\% then micro-hardness and fracture strength of composite were significantly enhanced as compared to the matrix alloy and almost two times higher than that of the base alloy. The improved mechanical properties could be attributed to the grains refinement of matrix and also the uniform dispersion of $\mathrm{B}_{4} \mathrm{C}$-particles resulted in superior interfacial bonding between both the constituents (matrix-reinforcement) of the composite.

Selvam et al. [45] examined the hardness and UTS of the AA6061 matrix composite reinforced with $(0,4,8$, 12 wt.\%) fly ash particles fabricated via compo-casting technique. The addition of fly ash particles in the AMC enhanced the mechanical properties like micro-hardness and ultimate tensile strength. Maximum micro-hardness and tensile strength were obtained for $12 \mathrm{wt} . \%$ fly ash particles addition, while minimum percentage elongation was achieved at 12 wt.\%. Homogeneous dispersion and good bonding between the matrix and particulates were the factors which could improve the mechanical properties of metal matrix composite. Li et al. [46] examined the distribution behaviour of $3 \mathrm{wt} . \% \mathrm{TiB}_{2}$-particles and the influ- 
ence of these particles on the mechanical characteristics of A390 alloy composite. The composite was produced by melt reaction technique. The tensile strength, percentage elongation and hardness of the composite were enhanced as the number of $\mathrm{TiB}_{2}$-particles increased. The major factors affecting the mechanical properties are $\mathrm{TiB}_{2}$ distribution in the matrix and strong interfacial bonding between both the constituents of composite.

Kalaiselvan et al. [47] evaluated the various mechanical and micro-structural characteristics of AA6061 AMCs reinforced with $(4,6,8,10,12$ wt. $\%) \mathrm{B}_{4} \mathrm{C}$-particles. The composite was produced through improved stir casting technique. Micro/macro hardness and UTS of the AMCs were enhanced as the weight content of $\mathrm{B}_{4} \mathrm{C}$-particles increased. Maximum hardness (micro/macro) and UTS was achieved at $12 \mathrm{wt} . \%$ particle addition. The enhancement in the mechanical properties was achieved by the increased surface area of the reinforcement particles and decreased grain size of the matrix. Higher restrictions against the plastic deformation improved the mechanical properties of the composite.

Song [48] investigated the influence of various volume content $(0,4,8,12,16,20 \%)$ of SiC-particle on the mechanical behaviour such as yield strength, tensile strength and elongation of AMC. The composite was fabricated through powder metallurgy technique. The improved tensile and yield strength of AMC were obtained by increasing the number of SiC-particles but elongation decreased with the number of SiC-particles. The grain refinement could be the reason for the enhancement in the mechanical behaviour of AMC. Arik [49] fabricated the AMCs reinforced with $\left(5,10,15\right.$ wt.\%) $\alpha$ - $\mathrm{Si}_{3} \mathrm{~N}_{4}$-particles through powder metallurgy technique. The composite mixture was produced by ball milling followed by mechanical alloying and prepared powder samples were sintered at different temperatures like $620,640,660,680^{\circ} \mathrm{C}$ and the influence of particle content, mechanical alloying on the mechanical properties of pure aluminium metal matrix composite was evaluated. The mechanical alloying of the prepared powder samples increased the hardness as well as the density and rupture strength of the composite. Maximum value of hardness and rupture strength was achieved for $10 \mathrm{wt} . \%$ particle reinforced mechanically alloyed sample at $660^{\circ} \mathrm{C}$ sintering temperature.

Canakci and Varol [50] have evaluated the influence of (2.5, 5 and 10 wt.\%) SiC-particles and (10, 20, 30 and 50 wt.\%) Al powder particles on the mechanical characteristics of AA7075 alloy composite. The composite was fabricated through powder metallurgy along with hot pressing technique. The hardness of the composite was enhanced as the amount of hard $\mathrm{SiC}$ particles increased. Maximum hardness of composite was obtained at 80 HBN for 10 wt.\% SiC and $10 \mathrm{wt} . \% \mathrm{Al}$ powders. It was also noticed that by increasing the content of $\mathrm{Al}$ powder, the green density of the composite has also been enhanced. Wang et al. [51] reported the effect of $5 \mathrm{wt} . \% \mathrm{TiB}_{2}$-particles on mechanical characteristics such as yield strength, UTS and percentage elongation of aluminium matrix master composite fabricated through flux assisted synthesis using mechanical stirring followed by an improved halide salt route condition. The effect of holding duration, reaction temperature and stirring during reaction on mechanical characteristics of the composite was evaluated. It was found that UTS, yield strength of prepared composite through halide salt route were found to be improved in-comparison-with the unreinforced alloy for above mentioned factors. Dolatkhah et al. [52] fabricated the AA5052 alloy composite filled with micro $(5 \mu \mathrm{m})$ and nano $(50 \mathrm{~nm})$ SiC-particles through FSP. Influence of various FSP parameters like tool rotational speed, traverse speed and particle size on the micro-hardness and wear properties of AMCs was investigated. The wear resistance and hardness of the composite were improved as the particle size of SiC was reduced. The enhanced mechanical behaviour was due to the refinement of grains of Al matrix with the addition of nano-SiC particles. Ozdemir et al. [53] reported the fabrication of AA2017 alloy composite reinforced with 5 and 15 vol.\% $\mathrm{SiC}$ and $\mathrm{Al}_{2} \mathrm{O}_{3}$ particles through semi-solid squeeze forming technique. The particle sizes were varied from 15 to $55 \mu \mathrm{m}$ as coarse reinforcement and 0.2 to $2 \mu \mathrm{m}$ as fine reinforcement. The effect of particles weight content and particles size on mechanical properties of AMC was investigated. The UTS and yield strength of the fine particles reinforced composite were found greater than the coarse particles reinforced composites and maximum UTS of 400 MPa was achieved for $15 \mathrm{vol} . \%$ fine $\mathrm{SiC}$ reinforcement. The reduced ductility was due to defects like micro crack generation and small band like oxides.

Rajaram et al. [54] determined the influence of graphite particles addition and strain rate on the various mechanical characteristics such as the yield strength, UTS and percentage elongation of Al-Si alloy reinforced with graphite particles and compared with the base alloy. The yield strength and UTS of the composite was higher than the base alloy. The UTS of the composite had shown a slightly decreasing trend by increasing the strain rate from $10^{-2}$ to $10^{-4} \mathrm{~s}^{-1}$. Maximum yield strength around $200 \mathrm{MPa}$ of composite was obtained for $10^{-3} \mathrm{~s}^{-1}$. Toptan et al. [55] added 10 wt. $\% \mathrm{~B}_{4} \mathrm{C}$ - particles in the AA1070 and AA6063 aluminium matrix through liquid metallurgy route and also the reaction was done with titanium containing flux to remove the problem of wetting of $\mathrm{B}_{4} \mathrm{C}$-particles with the 
Al alloys. A reaction layer containing $\mathrm{TiC}$ and $\mathrm{TiB}_{2}$ was formed on the interface of the matrix and reinforcement by the addition of $\mathrm{K}_{2} \mathrm{TiF}_{6}$ flux. This thin layer improved the wettability and interface bonding strength between the matrix and particles. Vencl et al. [56] fabricated the particulate reinforced A356 alloy composites filled with 10 wt. $\% \mathrm{Al}_{2} \mathrm{O}_{3}$ having $35 \mu \mathrm{m}$ particle size, $10 \mathrm{wt} . \% \mathrm{SiC}$ having $39 \mu \mathrm{m}$ particle size and (10 wt. $\% \mathrm{SiC}+1 \mathrm{wt} . \%$ graphite). The composite was fabricated through compo-casting technique. Various mechanical and wear characteristics of AMCs were investigated and also made a comparison with the heat treated matrix. The wear resistance, coefficient of friction, micro-hardness and yield strength of fabricated composite with $10 \mathrm{wt} . \% \mathrm{SiC}$ - particles were more than that of 10 wt. $\% \mathrm{Al}_{2} \mathrm{O}_{3}$-particles reinforced composite while graphite particles further enhanced the tribological properties. Maximum value of micro-hardness was $82.8 \mathrm{HV}$ and maximum value of yield strength was $198 \mathrm{MPa}$ for $10 \mathrm{wt} . \%$ SiC-particles composites.

Jinfeng et al. [57] determined the influence of $5 \%$ mass fraction of graphite particles and $40 \%$ mass fraction of $\mathrm{SiC}$ particles reinforcement on wear characteristics and mechanical properties of AA2024 alloy composite under dry sliding conditions. The addition of graphite reduced the friction coefficient and improved the wear resistance of the composite due to the formation of lubrication tribo-layer having iron-oxide, graphite and fractured SiC-particles. The tensile strength and elastic modulus of $\mathrm{Al} / \mathrm{SiC}$ composite were greater than the $\mathrm{Al} / \mathrm{SiC} / \mathrm{Gr}$ composites. It was attributed to the reduced hardness of composite due to the soft lubricating nature of graphite.

Yang et al. [58] discussed the fabrication of AA2024 matrix composite reinforced with $36 \mathrm{vol} . \% \mathrm{Si}_{3} \mathrm{~N}_{4}$-particles with particles size $0.2 \mu \mathrm{m}$. The fabrication was done through squeeze casting method followed by extrusion deformation. Influence of this extrusion deformation on mechanical characteristics was investigated. The tensile strength of $\mathrm{Si}_{3} \mathrm{~N}_{4}$-particles reinforced aluminium matrix composite was significantly improved due to the precipitation strengthening after T6 treatment and also due to the extrusion deformation which enhanced the bonding strength between matrix-reinforcement. Maximum tensile strength was $497.1 \mathrm{MPa}$ and maximum elastic modulus was 151.7 MPa after extrusion deformation. Yuan et al. [59] have fabricated the high strength Al-Zn-Mg-Cu matrix composite reinforced with 15-20 vol.\% of SiC-particles having size of $5 \mu \mathrm{m}$. The composite was fabricated through spray deposition method followed by extrusion. Various mechanical and micro-structural characteristics were studied. It was found that extruded composite samples have shown superior bonding between matrix-reinforcement. The max- imum tensile strength was $785 \mathrm{MPa}$ for heat treatment at $470^{\circ} \mathrm{C}$ for $1 \mathrm{~h}+490^{\circ} \mathrm{C}$ for $1 \mathrm{~h}$.

Ahamed et al. [60] evaluated the influence of ( 0.75 to 1.5 wt.\% ) nano $\mathrm{Al}_{2} \mathrm{O}_{3}$ and $\mathrm{Y}_{2} \mathrm{O}_{3}$ particulate addition on the mechanical behaviour of AA6063 alloy. The composite was fabricated through mechanical milling and mechanical alloying along with hot extrusion. The yield strength, ultimate tensile strength and hardness of AMCs were enhanced when compared with the unreinforced $\mathrm{Al}$ alloy. The improved mechanical properties may be attributed to better distribution of nano particulates, grain refinement, minimal porosity and good interfacial bonding between $\mathrm{Al}$ matrix and ceramic particles. The maximum value of hardness, yield strength and UTS were $76 \mathrm{MPa}, 484 \mathrm{MPa}$ and $497 \mathrm{MPa}$ respectively for $\mathrm{AA} 6063 / 0.75 \mathrm{Al}_{2} \mathrm{O}_{3} / 0.75 \mathrm{Y}_{2} \mathrm{O}_{3}$ hybrid composite. Beffort et al. [61] discussed the influence of alloying and heat treatment of pure $\mathrm{Al}$ matrix composite reinforced with $60 \mathrm{vol} . \% \mathrm{SiC}$ particles on various mechanical characteristics. The composite was fabricated through liquid metal infiltration. Different alloying elements such as $\mathrm{Mg}, \mathrm{Cu}$, and $\mathrm{Zn}$ were added into the matrix in order to improve the mechanical characteristics of AMCs. It was observed that $\mathrm{Mg}$ was the element which affects both the matrix material and interface of the matrix and reinforcement. It was observed that the elastic modulus of AMC was not considerably affected by alloying of matrix and heat treatment rather than it was influenced by the volume content of SiC-particles and its value was in the range of 200$210 \mathrm{GPa}$. Maximum bending strength of $700 \mathrm{MPa}$ could be achieved by making $\mathrm{AlCu}_{4} \mathrm{Mg} 1 \mathrm{Ag}$ alloy reinforced with 60 vol.\% SiC-particles followed by T6 heat treatment.

Mondal et al. [62] evaluated the influence of SiC content and age hardening on mechanical characteristics such as yield strength, ductility, elastic limit and Young's modulus of 5 wt.\% and 10 wt.\% SiC reinforced AA2014 alloy composite and compared with the base alloy. The composite was fabricated through liquid metallurgy technique. It was observed that the hardness of the AMCs in heat treated condition was significantly enhanced as compared to the base alloy and as cast AMCs. The maximum value of hardness, Elastic modulus, Yield strength and Fracture strength was $160 \mathrm{HV}, 94 \mathrm{GPa}, 360 \mathrm{MPa}, 585 \mathrm{MPa}$ respectively for $10 \mathrm{wt} . \% \mathrm{SiC}$ filled composite after heat treatment. It was found that by increasing the weight percentage of $\mathrm{SiC}$, the mechanical characteristics were also increased. Boddapati et al. [63] have discussed the influence of volume content of $\mathrm{AlN}$ and $\mathrm{Al}_{2} \mathrm{O}_{3}$-particles sizes $(25,53,90$ and $180 \mu \mathrm{m}$ ) on different mechanical properties such as crack growth resistance, Young's modulus, thermal diffusivity and coefficient of thermal expansion of AMCs. The composite was fabricated through pressure less infiltra- 
tion technique. The crack growth resistance was found to be reduced from $19.3 \mathrm{MPa} \mathrm{m}^{1 / 2}$ to $6.2 \mathrm{MPa} \mathrm{m}^{1 / 2}$ by increasing the volume fraction of AlN particles up to $24 \%$ and also the alumina particle size. Thermal diffusivity and CTE were also reduced by increasing the content of AlN particles. Zawrah and Aly [64] investigated the effect of $\mathrm{Al}_{2} \mathrm{O}_{3}$-SiC-mullite-particles on mechanical behaviour and microstructure of pure aluminium matrix composite. The composite was fabricated through powder metallurgy technique. The different composite batches were taken as M1 (40 wt.\% alumina + 30 wt.\% SiC), M2 (35 wt.\% alumina + 35 wt.\% SiC), M3 (30 wt.\% alumina + 30 wt.\% SiC), M4 (15 wt.\% alumina + 45 wt.\% SiC), M5 (30 wt.\% alumina +25 wt. $\% \mathrm{SiC}$ ). It was concluded that the Young's modulus and residual stress has been improved significantly with the addition of SiC-particles. The maximum compressive strength was achieved for M2 and M5 composite batches due to their higher densification nature. Wong et al. [65] have done the fabrication of aluminium hybrid MMCs using disintegrated melt deposition technique. Pure aluminium alloy 1050 was used as matrix material and $\mathrm{SiC}$ particles (particle size of $25 \mu \mathrm{m}$ ) with galvanized iron mesh (diameter $0.7 \mathrm{~mm}$ ) were used as reinforcement. The effect of hybrid reinforcement such as galvanized iron mesh and $\mathrm{SiC}$ particulates on the mechanical and physical properties of AMCs was also investigated. The macro-hardness, yield strength and UTS of aluminium hybrid composite were significantly improved as compared with unreinforced alloy. The improved mechanical characteristics were due to the incorporation of hard $\mathrm{SiC}$ reinforcement and also the higher resistance to the plastic deformation of matrix.

\section{On fabrication of Aluminium alloyed composites}

With wide variety acceptance of AMCs in marine, aircrafts, automotive, packaging, consumer goods etc., the fabrication procedure of such composites requires paramount at tention. Consequently material scholars contribute their research in this directions, like Sulaiman et al. [66] fabricated the Al-12Si (LM6) matrix composite reinforced with $10 \mathrm{wt} . \% \mathrm{SiC}$ particles and (0.02, $0.5 \mathrm{wt} . \%) \mathrm{Al}-10 \mathrm{Sr}$ through vortex method and discussed the influence of different weight content of strontium as a modifier on the mechanical behaviour of Al-12Si alloy. The ultimate tensile strength of the alloy was enhanced by incorporating $\mathrm{SiC}$ and strontium particles. It was due to the superior bonding between both the constituents (particles and matrix) of composite. The maximum hardness was obtained for $0.5 \mathrm{wt} . \% \mathrm{Sr}+$
10 wt.\% SiC reinforced composite. Reddy et al. [67] developed the pure $\mathrm{Al}$ matrix composite filled by $(5,10$ and 15 vol.\%) $\mathrm{Al}_{2} \mathrm{O}_{3}$ particles through microwave assisted sintering method along with hot extrusion. The influence of volume content of $\mathrm{Al}_{2} \mathrm{O}_{3}$ particles on various physical and mechanical characteristics was evaluated. It was found that as the concentration of $\mathrm{Al}_{2} \mathrm{O}_{3}$ particles increased, the mechanical properties such as micro-hardness, yield strength, UTS and young's modulus were also increased but the ductility and coefficient of thermal expansion were decreased. The improvement in mechanical properties may be due to the interfacial bonding and uniform distribution of ceramic particles. The maximum UTS was around $154 \mathrm{MPa}$ and maximum yield strength was about $139 \mathrm{MPa}$ which was more in comparison to the matrix alloy. Ghasali et al. [68] have done the fabrication of hybrid AMCs having pure $\mathrm{Al}$ and 1056AA reinforced with $15 \mathrm{wt} . \%$ $\mathrm{SiC}$ and 7 wt.\% TiC-particles through microwave and conventional sintering methods. The mechanical characteristics of AMCs were significantly enhanced by the microwave sintering of AA1056 matrix composite. Maximum bending strength was around $340 \mathrm{MPa}$ and micro-hardness was about $192 \mathrm{HV}$ for sintering at $750^{\circ} \mathrm{C}$. It was due to the uniform particle distribution of both the reinforcement after microwave sintering method.

Pozdniakov et al. [69] produced AMCs having Al-5Cu alloy as matrix material and 2, 5 and 7 wt.\% of $\mathrm{B}_{4} \mathrm{C}$ particles as reinforcement. Fabrication of composite was performed by using both stir casting and squeeze casting techniques. It was found that coefficient of thermal expansion was decreased as the reinforcement content increased for both stir and squeeze casting samples. Also, the yield strength of the composite enhanced as the volume fraction of reinforcement particles increased. Maximum yield strength was $260 \mathrm{MPa}$ for $7 \mathrm{wt} . \% \mathrm{~B}_{4} \mathrm{C}$-particles reinforcement. UTS was also improved by $19 \%$ as compared with the $\mathrm{A} 336$ alloy for $7 \mathrm{wt} . \% \mathrm{~B}_{4} \mathrm{C}$ - particle composite. Selvakumar et al. [70] investigated the mechanical properties of AA6082 alloy reinforced with $(0,6,12,18$ vol.\%) molybdenum (Mo) particles. The composite was fabricated through friction stir processing technique. The UTS of the composite was increased without reduction in the ductility with the Mo particles due to the uniform distribution and well bonding of the particles with the aluminium matrix. The UTS was significantly improved from $222 \mathrm{MPa}$ for 0 vol. $\%$ to $303 \mathrm{MPa}$ for $18 \mathrm{vol}$ \% Mo particles addition. Mohanavel et al. [71] fabricated the in-situ AA2014 alloy composite reinforced with (0, 4, 8 wt.\%) $\mathrm{ZrB}_{2}$-particles by using the exothermic salt metal reaction method. The effect of fabrication technique and weight content of reinforced particles on hardness and tensile strength was investigated. 
The mechanical characteristics of the composite were enhanced due to the increased weight content and uniform distribution of $\mathrm{ZrB}_{2}$-particles. Maximum hardness and tensile strength were achieved for $8 \mathrm{wt} . \% \mathrm{ZrB}_{2}$ reinforced composite. Grain refinement was also the reason for the improved mechanical properties.

Murthy et al. [72] reported the fabrication of AA7075 matrix hybrid composite reinforced with (2.5 to $10 \mathrm{wt} . \%$ ) $\mathrm{TiO}_{2}$ and fixed 3 wt.\% fly ash particles through stir casting followed by hot forging. The compressive strength was significantly enhanced with the addition of both the reinforcement and further increased as the weight percentage of $\mathrm{TiO}_{2}$-particles increases. The maximum compressive strength was achieved $421 \mathrm{MPa}$ for $3 \mathrm{wt} . \%$ fly ash and 10 wt. $\% \mathrm{TiO}_{2}$ reinforced hybrid composite. The mechanical characteristics were found to be enhanced by the uniform distribution of particles, grain refinement and generation of dislocations. The CTE and thermal conductivity were found to be reduced by increasing the weight percent of $\mathrm{TiO}_{2}$-particles. Kumar et al. [73] produced the AA6063 AMCs reinforced with (2, 4, 6, 8, 10 wt.\%) TiC-particles through stir casting technique. Various mechanical characteristics such as density, hardness, impact strength and tensile strength were also investigated. The tensile strength and hardness of the composites were improved with the addition of TiC-particles, but the impact strength had shown reverse trend by increasing the number of TiC-particles. The increased tensile strength can be attributed to the strong interface strength between both the constituents of the composite. Absence of pores was also contributed for enhancing the strength of the composite. The maximum tensile strength was obtained around 150 $\mathrm{N} / \mathrm{mm}^{2}$ for $10 \mathrm{wt} . \%$ TiC reinforced composites. Kandpal et al. [74] performed the fabrication of AA6061 AMCs filled with $\left(5,10,15\right.$ and 20 wt.\%) of $\mathrm{Al}_{2} \mathrm{O}_{3}$-particles. The composite was fabricated through stir casting technique. The uniformly distribution of reinforcement particles in the matrix and superior bonding was obtained between the matrix and reinforcement which enhanced micro-hardness and UTS of the aluminium metal matrix composite. Maximum tensile strength was obtained $310 \mathrm{MPa}$ and maximum hardness was $89.91 \mathrm{VHN}$ for $20 \mathrm{wt} . \% \mathrm{Al}_{2} \mathrm{O}_{3}$ reinforced composite.

Shalaby et al. [75] performed the fabrication of A359 cast alloy matrix composite reinforced with 5 to $15 \mathrm{wt} . \%$ AlN-particles using stir and squeeze casting techniques. Various thermal and mechanical characteristics of fabricated composites were evaluated. The hardness, ultimate compressive and yield strength of the composite were enhanced as the weight percentage of AlN-particles increased from 5 to $15 \mathrm{wt} . \%$. The maximum peak hardness during aging was observed $145 \mathrm{Hv}$ for 15 wt.\% AlN. The yield strength and UTS were significantly raised up to 314 and $473 \mathrm{MPa}$ respectively. Ashwath and Xavior [76] fabricated the AA2900 matrix composite reinforced with (10, 15 and $20 \mathrm{wt} . \%$ ) of $\mathrm{SiC}, \mathrm{Al}_{2} \mathrm{O}_{3}$ and graphene powders through ball milling followed by compaction and microwave sintering. The influence of ball milling and reinforcement content on the mechanical properties of AMCs was also investigated. It was concluded that $10 \mathrm{wt} . \%$ or less addition of graphene was feasible to get better compact in sintering and to improve the mechanical properties of AMCs. The maximum hardness was 40.22 HBN for AA2900/20 wt.\% SiC composite.

Tahamtan et al. [77] reported the fabrication of A206 alloy composite reinforced with 5 vol.\% $\mathrm{Al}_{2} \mathrm{O}_{3}$-particles through the combination of ball milling and stir casting techniques. The effect of various fabricating parameters such as casting temperature, reinforcement particle size and ball milling on tensile characteristic was evaluated. It was found that as the casting temperature was reduced, the interfacial reaction products and porosity was also lowered and subsequently enhanced the tensile properties of the composite. The tensile strength was also increased due to reduction in the reinforcement particle size from micro to nano particulate size. The wettability between Al matrix and alumina particles was improved due to the addition of milled alumna particles.

Liu et al. [78] performed the fabrication of Al-12Si-4Cu based composite reinforced with $\mathrm{TiB}_{2}$-particles through the addition of Ti-B pellets generated from a mixture of $\mathrm{Ti}$ and $\mathrm{B}$ powder in the molten $\mathrm{Al}$ matrix. The influence of high intensity ultrasonic vibration on the microstructure has been discussed and found that homogeneous microstructure of the composite has been achieved as a result of ultrasonic vibration. Wang et al. [79] reported the production of Al-Cu based MMCs reinforced by SiC-particles through the powder metallurgy technique. The influence of extrusion and volume content of filled particles has been discussed. It was found that homogeneous distribution of SiC- particles in the $\mathrm{Al}$ matrix has been increased which enhanced the interfacial bonding strength of the composite as a result of extrusion. Cheng et al. [80] reported three different surface modification techniques for the fabrication of AMCs filled with SiC-particles through powder metallurgy technique. It was found that the elastic modulus, yield strength and tensile strength of the aluminium matrix composite were significantly enhanced as compared with unreinforced $\mathrm{Al}$ alloy due to the homogeneous distribution of SiC-particles into the $\mathrm{Al}$ matrix. Zeng et al. [81] analysed the fabrication of aluminium matrix composite reinforced by $\mathrm{SiC}$-particles through powder met- 
allurgy route. Effective load transfer has been obtained between the matrix of 6066Al alloy and filled particles. Homogeneous distribution of SiC-particles into the matrix, grain refinement of the matrix and dislocation strengthening were the reasons, which enhanced the mechanical characteristics of the composite. Ren et al. [82] reported the synthesis of Al-8Mg alloy based composite reinforced with 55 volume $\%$ of SiC-particles through pressureless infiltration. It was found that $\mathrm{Si}$ addition in the alloy decreased the coefficient of thermal expansion and enhanced the thermal conductivity of the composite. It may be due to the influence of Si content on the wettability and interfacial reaction.

Hassan et al. [83] prepared the aluminium matrix composite having cast Al-Si-Fe alloy as matrix and SiCparticles as reinforcement by double stir casting method. It was found that various mechanical characteristics such as hardness, UTS and yield strength have been improved as the number of SiC-particles increased in the matrix. The enhancement in mechanical characteristics was achieved by incorporating hard particles in the ductile matrix. Gui et al. [84] studied the thermal conductivity of AMCs filled with silicon carbide particles fabricated through ball milling and plasma spraying technique. It was found that the thermal conductivity has been reduced at room temperature. It may be attributed to the extended milling time and small size of silicon carbide particles.

Cocen et al. [85] evaluated the ductility and strength of AMCs filled with silicon carbide particles. AMCs were fabricated through casting followed by extrusion. It was found that after extrusion, the uniform distribution of $\mathrm{SiC}$ particles has been obtained which subsequently enhanced the yield strength and tensile strength but reduced the ductility of the composites as the amount of SiC particles increases. Azim et al. [86] discussed the vortex method for the production of AMCs filled with different volume fractions of $\alpha$ - $\mathrm{Al}_{2} \mathrm{O}_{3}$-particles. To create the vortex, an impeller was used which worked as a stirrer. In order to decrease the required stirring time, a special surface treatment has been given to alumina particles. The addition of $\mathrm{Al}_{2} \mathrm{O}_{3}$-particles reduced the grain size of the matrix and improved the yield strength and wear resistance of the Al matrix but the UTS and ductility of the $\mathrm{Al}$ alloy has been decreased.

\section{On thermal and thermo-mechanical behaviour of Aluminium alloyed composites}

The thermal properties (like thermal conductivity and thermal expansion) of materials have significance importance for designing the components (for various machine components such as heat exchangers, heat sinks etc.) subjected to variable service temperatures. The research contribution by various scholars are as follows: Sharma et al. [87] analysed the thermal expansion of SiC reinforced aluminium metal composite. Three types of composites have been fabricated having Al-Si-Mg alloy as matrix material. The coefficient of thermal expansion was evaluated for different factors such as micro-structural morphologies, properties of constituents and the presence of thermal residual stresses. It was found that the thermal expansion behaviour has been significantly affected by the contact state of reinforced particles but the CTE of composites was not much affected due to the thermal residual stresses. Montalba et al. [88] evaluated the damping characteristics of Al metal alloy composite reinforced with $\mathrm{SiC}$ and PLZT (Piezoelectric lead Lanthanum Zirconate Titanate) particles. Dynamic mechanical analysis was carried out as function of temperature in order to evaluate the damping capacity of the composite. It was observed from the analysis of Tan $\delta$ value and storage modulus value that both the reinforcements were enhanced the damping capacities of composites at higher temperature without affecting the mechanical properties of matrix and reinforcement. Hu et al. [89] discussed the damping properties of AMCs having TiNi fibers and SiC-particles as reinforcements. The damping characteristic was determined with respect to strain rate at room temperature and also with respect to temperature at different frequency. The damping capacity of composites was reduced at room temperature due to more gliding of dislocation as content of $\mathrm{SiC}$ particles was increased. Kumar et al. [90] fabricated AMC reinforced with cenosphere powder through powder metallurgy route. The coefficient of thermal expansion was determined for a temperature of $500^{\circ} \mathrm{C}$ and rate of heating was $3^{\circ} \mathrm{C} / \mathrm{min}$. It was observed that the coefficient of thermal expansion was reduced as the volume content of cenosphere increased from 10 to 50 volume\%. Vannan et al. [91] discussed the thermal behaviour of AMCs having Al 7075 alloy as matrix and basalt fibre as reinforcement. The composite was fabricated through liquid metallurgy technique. The coefficient of thermal expansion was analyzed in a temperature range of $50^{\circ} \mathrm{C}$ to $300^{\circ} \mathrm{C}$. Thermal mechanical 
analyzer was used to measure the $\mathrm{CTE}$ at $5^{\circ} \mathrm{C}$ per minute. It was concluded that the value of CTE was enhanced as the temperature increases but the value of CTE was reduced by increasing the content of basalt fibre reinforcement.

So et al. [92] discussed the fabrication of $\mathrm{SiC}$ coated carbon nano tube reinforced aluminium matrix composite. Thermal gravimetric analysis was done in order to find out the thermal properties of composite. It was observed from the TGA analysis that the oxidation temperature of CNT was enhanced with the formation of SiC layer which provide a protective atmosphere against oxidation and depends upon the content of SiC coating on CNT. Zhang et al. [93] reported the fabrication of $\mathrm{TiB}_{2}$-particles reinforced Al-Si matrix composite. Various thermal properties like coefficient of thermal expansion and thermal conductivity were analyzed. Lower thermal expansion coefficient and higher thermal conductivity were obtained after hot iso-static pressing. The enhanced thermal and mechanical properties were beneficial for electronic packaging applications. Fan et al. [94] fabricated AMCs reinforced with $10 \%$ mass fraction of $\mathrm{BaTiO}_{3}$ ceramic particulates through powder metallurgy technique followed by hot extrusion. Various damping characteristics of AMCs were investigated for temperature varying between $273 \mathrm{~K}$ and 573 $\mathrm{K}$. The damping capacity of fabricated composite was enhanced for temperature above $450 \mathrm{~K}$ due to improved dislocations density in the composite. The tensile strength of the composite was also improved by $42 \%$ when compared with unreinforced alloy.

\section{Conclusion}

It has been observed that ceramic particulates such as SiC, $\mathrm{Al}_{2} \mathrm{O}_{3}, \mathrm{~B}_{4} \mathrm{C}, \mathrm{Si}_{3} \mathrm{~N}_{4}$, TiC etc. reinforcements whether micro or nano-sized would significantly enhances both tribological and mechanical characteristics of aluminium alloys composites. Further, addition of solid lubricants like graphite, $\mathrm{MoS}_{2}$ etc. leads to enhancement in tribological properties by inducing firm tribo-film across interface real time. Many scholars reported effect of single reinforcement variations in Al MMCs, while binary or hybrid reinforcement variations are rarely reported, that leaves ample scope of research. Also, one can study the effect of inter-metallic particulates instead of ceramics in $\mathrm{Al}$ alloys and then makes comparative analysis reports. The homogeneous dispersion of micro- particulates in $\mathrm{Al}$ alloy matrix increases the interfacial bonding between matrix and reinforcement, leading to improvement in hardness, specific strength/stiffness, thermal re- sistance, wear resistance, fracture toughness, and corrosion resistance etc. Micro-sized ceramic particulates significantly enhance the mechanical features of the matrix by enhancing particle-hardening-mechanisms and structure stability. It leads to effective load transfer mechanism between matrix-reinforcement during tribological applications like brake rotors, cylinder liners, pistons etc. The wear of counter surface material is an important aspect, which must be considered for better efficiency of a tribosystem. The effects of ceramic particulates size, shape on various tribological and mechanical properties of AMCs need to be investigated along with wear mechanisms and wear morphology of AMCs to understand the mechanism at sub-surface level, that overall governs its behaviour.

\section{References}

[1] N. M. Kumar, S. S. Kumaran, and L. A. Kumaraswamidhas, J. Alloys Compd., 672 (2016) 238-250.

[2] L. Yuan, J. Han, J. Liu, and Z. Jiang, Tribol. Int., 98 (2016) 41-47.

[3] I. Dinaharan, N. Murugan, and A. Thangarasu, Eng. Sci. Technol. an Int. J., 19 (2016) 1132-1144.

[4] I. Dinaharan, R. Nelson, S.J. Vijay, and E.T. Akinlabi, Mater. Charact., 118 (2016) 149-158.

[5] K. K. Alaneme and K. O. Sanusi, Eng. Sci. Technol. an Int. J., 18 (2015) 416-422.

[6] A. Pramanik, Trans. Nonferrous Met. Soc. China, 26 (2016) 348358.

[7] B. A. Kumar, N. Murugan, and I. Dinaharan, Trans. Nonferrous Met. Soc. China, 24 (2014) 2785-2795.

[8] P. Ravindran, K. Manisekar, P. Rathika, and P. Narayanasamy, Mater. Des., 45 (2013) 561-570.

[9] R. Kumar and S. Dhiman, Mater. Des., 50 (2013) 351-359.

[10] T. Rajmohan, K. Palanikumar, and S. Ranganathan, Trans. Nonferrous Met. Soc. China, 23 (2013) 2509-2517.

[11] A. Devaraju, A. Kumar, and B. Kotiveerachari, Trans. Nonferrous Met. Soc. China, 23 (2013) 1275-1280.

[12] A. Mazahery and M. O. Shabani, Trans. Nonferrous Met. Soc. China, 23 (2013) 1905-1914.

[13] A. Mazahery and M. O. Shabani, Compos. Part B Eng., 43 (2012) 1302-1308.

[14] R. N. Rao, S. Das, D. P. Mondal, and G. Dixit, Tribol. Int., 53 (2012) 179-184.

[15] P. Ravindran, K. Manisekar, P. Narayanasamy, N. Selvakumar, and R. Narayanasamy, Mater. Des., 39 (2012) 42-54.

[16] R. N. Rao and S. Das, Mater. Des., 32 (2011) 1066-1071.

[17] Y. Sahin and V. Kilicli, Wear, 271 (2011) 2766-2774.

[18] R. N. Rao and S. Das, Mater. Des., 31 (2010) 1200-1207.

[19] G. N. Kumar, R. Narayanasamy, S. Natarajan, S. P. K. Babu, K. Sivaprasad, and S. Sivasankaran, Mater. Des., 31 (2010) 15261532.

[20] V. R. Rajeev, D. K. Dwivedi, and S. C. Jain, Tribol. Int., 43 (2010) 1532-1541.

[21] S. Natarajan, R. Narayanasamy, S. P. K. Babu, G. Dinesh, B. A. Kumar, and K. Sivaprasad, Mater. Des., 30 (2009) 2521-2531. 
[22] M. Kök, Compos. Part A Appl. Sci. Manuf., 37 (2006) 457-464.

[23] S. Zhiqiang, Z. Di, and L. Guobin, Mater. Des., 26 (2005) 454458.

[24] D. P. Mondal, S. Das, R. N. Rao, and M. Singh, Mater. Sci. Eng. A., 402 (2005) 307-319.

[25] Y. Sahin, Mater. Sci. Eng. A., 408 (2005) 1-8.

[26] K.R. Suresh, H.B. Niranjan, P.M. Jebaraj, and M.P. Chowdiah, Wear, 255 (2003) 638-642.

[27] K.L. Tee, L. Lu, and M.O. Lai, Wear, 240 (2000) 59-64.

[28] K. S. Al-rubaie, H. N. Yoshimura, and J. D. B. DeMello, Wear, 233235 (1999) 444-454.

[29] S. Wilson and A. T. Alpas, Wear, 196 (1996) 270-278.

[30] A. P. Sannino and H. A. Rack, Wear, 197 (1996) 151-159.

[31] Y. Shen, X. Li, T. Hong, J. Geng, and H. Wang, Mater. Sci. Eng. A., 655 (2016) 265-268.

[32] J. D. R. Selvam and I. Dinaharan, Eng. Sci. Technol. an Int. J., 20 (2017) 187-196.

[33] P. Sharma, S. Sharma, and D. Khanduja, J. Asian Ceram. Soc., 3 (2015) 352-359.

[34] G. Iacob, V.G. Ghica, M. Buzatu, T. Buzatu, and M.I. Petrescu, Compos. Part B Eng., 69 (2015) 603-611.

[35] R. Bauri, D. Yadav, C. N. S. Kumar, and B. Balaji, Mater. Sci. Eng. A., 620 (2014) 67-75.

[36] S. Ghanaraja, C. M. Ramanuja, C. J. G. Gowda, and K. S. Abhinandhan, Mater. Today Proc., 2 (2015) 1282-1290.

[37] G. Gautam, and A. Mohan, J. Alloys Compd., 649 (2015) 174-183.

[38] G. Han, W. Zhang, G. Zhang, Z. Feng, and Y. Wang, Mater. Sci. Eng. A., 633 (2015) 161-168.

[39] N. Kumar, R. K. Gautam, and S. Mohan, Mater. Des., 80 (2015) 129-136.

[40] N. B. Khosroshahi, R. T. Mousavian, R. A. Khosroshahi, and D. Brabazon, Mater. Des., 83 (2015) 678-688.

[41] S. Suresh, N. S. V. Moorthi, S. C. Vettivel, and N. Selvakumar, Mater. Des., 59 (2014) 383-396.

[42] S. P. Dwivedi, S. Sharma, and R. K. Mishra, Procedia Mater. Sci., 6 (2014) 1524-1532.

[43] X. Z. Kai, Z. Q. Li, G.L. Fan, Q. Guo, D. B. Xiong, W. L. Zhang, et al. Mater. Sci. Eng. A., 587 (2013) 46-53.

[44] R. Zheng, X. Hao, Y. Yuan, Z. Wang, K. Ameyama, and C. Ma, J. Alloys Compd., 576 (2013) 291-298.

[45] J. D. R. Selvam, D. S. R. Smart, and I. Dinaharan, Mater. Des., 49 (2013) 28-34.

[46] P. Li, Y. Li, Y. Wu, G. Ma, and X. Liu, Mater. Sci. Eng. A., 546 (2012) 146-152.

[47] K. Kalaiselvan, N. Murugan, and S. Parameswaran, Mater. Des., 32 (2011) 4004-4009.

[48] M. Song, Trans. Nonferrous Met. Soc. China, 19 (2009) 14001404.

[49] H. Arik, Mater. Des., 29 (2008) 1856-1861.

[50] A. Canakci and T. Varol, Powder Technol., 268 (2014) 72-79.

[51] Z. Chen, T. Wang, Y. Zheng, Y. Zhao, H. Kang, and L. Gao, Mater. Sci. Eng. A., 605 (2014) 301-309.

[52] A. Dolatkhah, P. Golbabaei, M.K.B. Givi, and F. Molaiekiya, Mater. Des., 37 (2012) 458-464.

[53] I. Ozdemir, S. Muecklich, H. Podlesak, and B. Wielage, J. Mater. Process. Technol. 211 (2011) 1260-1267.

[54] G. Rajaram, S. Kumaran, and S. Suwas, Mater. Sci. Eng. A., 528 (2011) 6271-6278.

[55] F. Toptan, A. Kilicarslan, A. Karaaslan, M. Cigdem, and I. Kerti, Mater. Des., 31 (2010) S87-S91.
[56] A. Vencl, I. Bobic, S. Arostegui, B. Bobic, A. Marinković, and M. Babić, J. Alloys Compd., 506 (2010) 631-639.

[57] L. Jinfeng, J. Longtao, W. Gaohui, T. Shoufu, and C. Guoqin, Rare Met. Mater. Eng., 38 (2009) 1894-1898.

[58] Z. Y. Xiu, G. Q. Chen, Y. M. Liu, W. S. Yang, and G. H. Wu, Trans. Nonferrous Met. Soc. China, 19 (2009) 373-377.

[59] W. Yuan, J. Zhang, C. Zhang, and Z. Chen, J. Mater. Process. Technol., 209 (2009) 3251-3255.

[60] H. Ahamed and V. Senthilkumar, Mater. Des., 37 (2012) 182-192.

[61] O. Beffort, S. Long, C. Cayron, J. Kuebler, and P. A. Buffat, Compos. Sci. Technol., 67 (2007) 737-745.

[62] D. P. Mondal, S. Das, K. S. Suresh, and N. Ramakrishnan, Mater. Sci. Eng. A., 460-461 (2007) 550-560.

[63] S.R. Boddapati, J. Rödel, and V. Jayaram, Compos. Part A Appl. Sci. Manuf., 38 (2007) 1038-1050.

[64] M. F. Zawrah and M. H. Aly, Ceram. Int., 32 (2006) 21-28.

[65] W. L. E. Wong, M. Gupta, and C. Y. H. Lim, Mater. Sci. Eng. A., 423 (2006) 148-152.

[66] S. Sulaiman, Z. Marjom, M. I. S. Ismail, M. K. A. Ariffin, and N. Ashrafi, Procedia Eng. 184 (2017) 773-777.

[67] M. P. Reddy, F. Ubaid, R. A. Shakoor, G. Parande, V. Manakari, A. M. A. Mohamed, and M. Gupta, Mater. Sci. Eng. A., 696 (2017) 60-69.

[68] E. Ghasali, R. Yazdani-rad, K. Asadian, and T. Ebadzadeh, J. Alloys Compd. 690 (2017) 512-518.

[69] A. V. Pozdniakov, A. Lotfy, A. Qadir, E. Shalaby, M. G. Khomutov, A. Y. Churyumov, and V. S. Zolotorevskiy, Mater. Sci. Eng. A., 688 (2017) 1-8.

[70] S. Selvakumar, I. Dinaharan, R. Palanivel, and B. Ganesh Babu, Mater. Charact., 125 (2017) 13-22.

[71] V. Mohanavel, M. Naveen Kumar, K. Mageshkumar, C. Jayasekar, N. Dineshbabu, and S. Udishkumar, Mater. Today Proc., 4 (2017) 3215-3221.

[72] K. V. S. Murthy, D. P. Girish, R. Keshavamurthy, T. Varol, and P. G. Koppad, Prog. Nat. Sci. Mater. Int., 27 (2017) 474-481.

[73] K. R. Kumar, K. Kiran, and V. S. Sreebalaji, J. Alloys Compd., 723 (2017) 795-801.

[74] B. C. Kandpal, J. Kumar, and H. Singh, Mater. Today Proc., 4 (2017) 2783-2792.

[75] E. A. M. Shalaby, and A. Y. Churyumov, J. Alloys Compd., 727 (2017) 540-548.

[76] P. Ashwath and M. A. Xavior, Procedia Eng., 97 (2014) 1027-1032.

[77] S. Tahamtan, A. Halvaee, M. Emamy, and M. S. Zabihi, Mater. Des., 49 (2013) 347-359.

[78] Z. Liu, Q. Han, J. Li, and W. Huang, J. Mater. Process. Technol., 212 (2012) 365-371.

[79] Z. Wang, M. Song, C. Sun, D. Xiao, and Y. He, Mater. Sci. Eng. A., 527 (2010) 6537-6542.

[80] N. P. Cheng, C. M. Li, Q. Hui, and Z. Q. Chen, Mater. Sci. Eng. A., 517 (2009) 249-256.

[81] N. P. Cheng, S. M. Zeng, and Z. Y. Liu, J. Mater. Process. Technol., 202 (2008) 27-40.

[82] S. Ren, X. He, X. Qu, I.S. Humail, and Y. Li, Mater. Sci. Eng. B Solid-State Mater. Adv. Technol., 138 (2007) 263-270.

[83] V. S. Aigbodion and S. B. Hassan, Mater. Sci. Eng. A., 447 (2007) 355-360.

[84] M. Gui, S.B. Kang, and K. Euh, Scr. Mater., 52 (2005) 51-56.

[85] O. Kazim, Compos. Sci. Technol., 62 (2002) 275-282.

[86] A. N. Azim, Y. Shash, S. F. Mostafa, and A. Younan, J. Mater. Process. Technol., 55 (1995) 199-205. 
[87] N. K. Sharma, R. K. Misra, and S. Sharma, Int. J. Solids Struct., 102-103 (2016) 77-88.

[88] C. Montalba, K. Ramam, D. G. Eskin, E. M. Ruiz-Navas, and O. Prat, Mater. Des., 69 (2015) 213-218.

[89] J. Hu, G. Wu, Q. Zhang, and H. Gou, Compos. Part B Eng., 66 (2014) 400-406.

[90] M.G.A. Kumar, S. Seetharamu, J. Nayak, and L.N. Satapathy, Procedia Mater. Sci., 5 (2014) 1066-1074.
[91] S. E. Vannan, S. P. Vizhian, and R. Karthigeyan, Procedia Eng., 97 (2014) 432-438.

[92] K. P. So, J. C. Jeong, J. G. Park, H. K. Park, Y. H. Choi, D. H. Noh, et al., Compos. Sci. Technol., 74 (2013) 6-13.

[93] L. Zhang, G.S. Gan, and B. Yang, Mater. Des., 36 (2012) 177-181.

[94] G. L. Fan, Z. Q. Li, and D. Zhang, Trans. Nonferrous Met. Soc. China, 22 (2012) 2512-2516. 